\title{
Reactivity of tetracyanoethylene (TCNE): Synthesis and catalytic properties of a nickel complex supported by pentacyanopropenide derived from TCNE
}

Yan Liu, Ling-Zhi Tang, Shu-Zhong Zhan*

College of Chemistry \& Chemical Engineering, South China University of Technology, Guangzhou 510640, China

\begin{abstract}
The reaction of 2,2-bipyridine (bpy), $\mathrm{NiCl}_{2} \cdot 6 \mathrm{H}_{2} \mathrm{O}$ and tetracyanoethylene (TCNE) affords a nickel complex, [Ni(bpy) $\left.)_{3}\right] \cdot(\mathrm{PCPP})_{2} \mathbf{1}$ (PCPP: pentacyanopropenide, a compound derived from TCNE). Its structure has been characterized by physics-chemical and spectroscopic methods. This complex can electrocatalyze hydrogen generation both from acetic acid, with a turnover frequency (TOF) of 152.88 moles of $\mathrm{H}_{2}$ per mole of catalyst per hour an overpotential (OP) of $941.6 \mathrm{mV}$ (in $\mathrm{CH}_{3} \mathrm{CN}$ ), and from aqueous buffer ( $\mathrm{pH} 7.0$ ) with a TOF of 1464 moles of $\mathrm{H}_{2}$ per mole of catalyst per hour at an OP of $837.6 \mathrm{mV}$.
\end{abstract}

Keywords: Nickel complex; molecular catalyst; proton or water reduction; $\mathrm{H}_{2}$ evolution

* Corresponding author. Fax: +86-20-87112053.

E-mail address: shzhzhan@scut.edu.cn (S.-Z. Zhan). 
We focus our works on tetracyanoethylene (TCNE) chemistry, because of its versatile reactions in different directions [1-5]. Additionally, TCNE also has the ability to accept one or two electrons to form anions and to bond with metal ions or complexes. So far, several molecular magnetic materials have been provided by reactions of TCNE with paramagnetic metal ions [5-9]. Despite these advances, few materials based on nickel complexes supported by TCNE are known. To meet this need, we tried the reaction of $\mathrm{NiCl}_{2} \cdot 6 \mathrm{H}_{2} \mathrm{O}$, 2,2-bipyridine (bpy) and tetracyanoethylene (TCNE) with a molar ratio set of 1:2:2. Surprisingly, an unexpected product, $\left[\mathrm{Ni}(\mathrm{bpy})_{3}\right] \cdot(\mathrm{PCPP})_{2}$ was obtained. In this paper, we describe the synthesis, structure and properties of this complex, as well as its electrocatalytic hydrogen generation from both acetic acid and aqueous buffer.

Experimentally, [Ni(bpy) $)_{3}$. $(\mathrm{PCPP})_{2} \mathbf{1}$ was formed by the reaction of $\mathrm{NiCl}_{2} \cdot 6 \mathrm{H}_{2} \mathrm{O}$, bpy and TCNE with a molar ratio set of 1:2:2 or 1:3:2 (Scheme 1) [10]. Based on the literature precedent $[2,11,12]$, a possible mechanism for the formation of $\mathrm{PCPP}^{-}$was illustrated by Scheme 2. The addition of nickel salt or bpy leads to the formation of [TCNE $]^{-}$, then provides an intermediate $\left[\mathrm{C}_{2}(\mathrm{CN})_{3}\right]$ by losing one $\mathrm{CN}^{-}$. Further reaction with water gives bicyanomethanide $\left[\mathrm{C}(\mathrm{CN})_{2}\right]^{--}$by losing one $\mathrm{NC}-\mathrm{CO}^{-}$. Finally, $\left[\mathrm{C}(\mathrm{CN})_{2}\right]^{-}$reacts with $\left[\mathrm{C}_{2}(\mathrm{CN})_{3}\right]^{\prime}$ provides $\mathrm{PCPP}^{-}$anion. The result is consistent with that TCNE undergoes numerous reactions [13]. As shown in Fig. S1, the infrared spectrum of 1 showed one $v(\mathrm{C} \equiv \mathrm{N})$ stretch at $2160 \mathrm{~cm}^{-1}$ at lower energy than that of the free tetracyanoethylene (2215 and $2258 \mathrm{~cm}^{-1}$ ) (Fig. S2), assigning to the cyanide mode of $\mathbf{1}$. To test the stability of complex $\mathbf{1}$, electronic spectra were measured in 
both organic and aqueous media. The UV-Vis spectrum of $\mathbf{1}$ in acetonitrile shows an absorption peak at $295 \mathrm{~nm}$ (Fig. S3), which corresponds to a pi-pi* transition of the bpy moiety. From Fig. S4, in buffered aqueous solutions at the $\mathrm{pH}$ range 2.0-12.0, the intensity of the absorption band at $295 \mathrm{~nm}$ increases, suggesting new components are being formed. These observations point to the formation of dinuclear or polynuclear species [14].
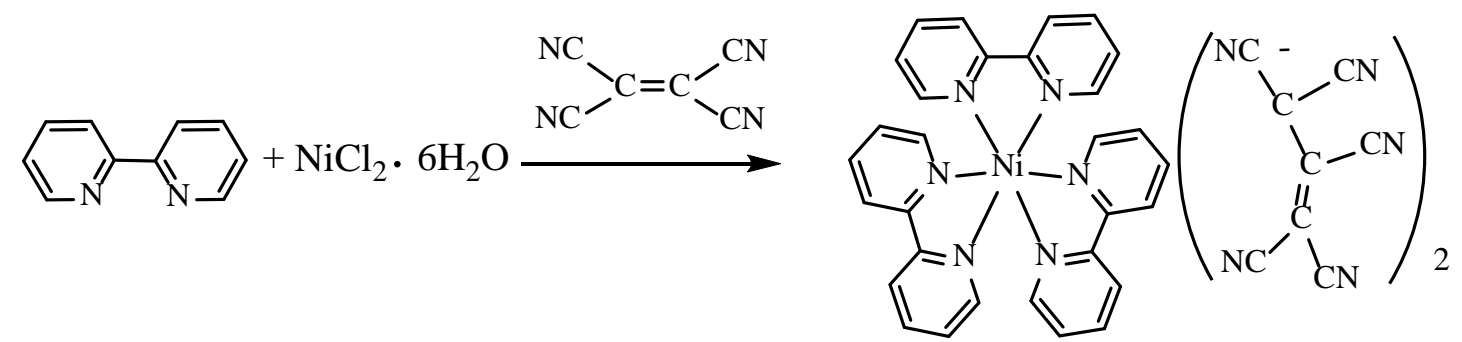

Scheme 1 Synthesis of complex 1.

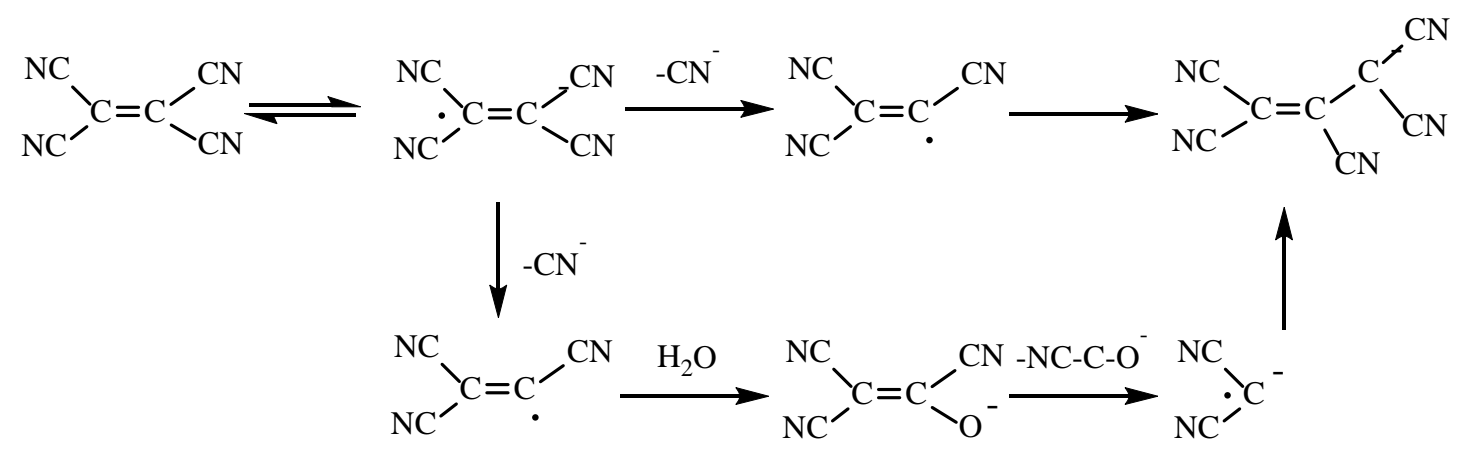

Scheme 2 The procedure for the formation of PCPP $^{-}$anion.

As shown in Fig. 1, X-ray structure of complex 1 revealed a six-coordinated nickel atom in an octahedral surrounding. The Ni-N bond lengths fall in the range 2.0633(15) to 2.0925(15) Å. In order to check the purity of complex 1, powder X-ray diffraction of the as-synthesized sample was measured at room temperature. According to Fig. S5, the peak positions of experimental patterns are in good 
agreement with the simulated ones, which clearly indicates good purity of the complex 1. Interestingly, the introduction of methanol into nomonuclear complex $\mathbf{1}$ led to the formation of a dimer. This was in agreement with result from ESI-MS measurement which exhibited one ion at a mass-to-charge ratio $(\mathrm{m} / \mathrm{z})$ of 277.1281, with the mass and isotope distribution pattern corresponding to that of $\left[(\text { bipy })_{6} \mathrm{Ni}_{2}\left(\mathrm{H}_{2} \mathrm{O}\right)_{3}\right]^{4+}$ (Fig. S6).

Fig. 1. ORTEP drawing of complex 1 with thermal ellipsoids on the 50\% probability level (hydrogen atoms are not shown).

It has been shown that coordinatively unsaturated complexes can electro-catalyze hydrogen production via an unstable hydride intermediate $[15,16]$. To explore if this coordinatively saturated complex also can act as an electrocatalyst, the electrochemical measurements for complex 1 were conducted in $\mathrm{CH}_{3} \mathrm{CN}$ with $0.10 \mathrm{M}$ $\left[(\mathrm{n}-\mathrm{Bu})_{4} \mathrm{~N}\right] \mathrm{ClO}_{4}$ as the supporting electrolyte. Fig. 2 represented the $\mathrm{CV}$ of $0.48 \mathrm{mM}$ complex 1, and two reversible redox couples were found in the potentials of -1.47 and $2.04 \mathrm{~V}$ versus $\mathrm{Fc}^{+} / \mathrm{Fc}$, which can be assigned to the couples of $\mathrm{Ni}^{\mathrm{II}} / \mathrm{Ni}^{\mathrm{I}}$ and $\mathrm{Ni}^{\mathrm{I}} / \mathrm{Ni}^{0}$, respectively. According to Fig. S7, the current responses of the redox events at -2.06 and $-1.54 \mathrm{~V}$ versus $\mathrm{Fc}^{+} / \mathrm{Fc}$ showed linear dependence on the square root of the scan rate, indicating this is a diffusion-controlled process.

Fig. 2. Cyclic voltammogram (CV) of $0.48 \mathrm{mM}$ complex 1 in $\mathrm{CH}_{3} \mathrm{CN}$. Conditions: room temperature, $0.10 \mathrm{M}\left[\mathrm{n}-\mathrm{Bu}_{4} \mathrm{~N} \mathrm{ClO}_{4}\right.$ as supporting electrolyte, scan rate: 100 
$\mathrm{mV} / \mathrm{s}$, glassy carbon working electrode (1 mm diameter), Pt counter electrode, $\mathrm{Ag} / \mathrm{AgNO}_{3}$ reference electrode. Ferrocene internal standard $\left({ }^{*}\right)$.

To determine catalytic activity of this nickel complex, cyclic voltammograms of complex 1 were measured in the presence of acetic acid. From Fig. 3 it can be seen that the catalytic current near -2.06 and $-1.54 \mathrm{~V}$ versus $\mathrm{Fc}^{+} / \mathrm{Fc}$ increased markedly with the sequential increments of acetic acid concentration (from 0.00 to $1.36 \mathrm{mM}$ ). This rise in current can be attributed to the catalytic generation of $\mathrm{H}_{2}$ from acetic acid [17]. The result indicates that $\mathrm{H}_{2}$ production electrocatalyzed by complex $\mathbf{1}$ requires the reduction potentials of $\mathrm{Ni}(\mathrm{II})$ to $\mathrm{Ni}(\mathrm{I})$ and $\mathrm{Ni}(\mathrm{I})$ to $\mathrm{Ni}(0)$. Interestingly, with the acetic acid concentration increased from 0.0 to $1.36 \mathrm{mM}$ (Fig. 3), the reduction potential near $-1.54 \mathrm{~V}$ versus $\mathrm{Fc}^{+} / \mathrm{Fc}$ remained almost constant and the wave near $-2.06 \mathrm{~V}$ versus $\mathrm{Fc}^{+} / \mathrm{Fc}$ moved to more anodic value from $-2.06 \mathrm{~V}$ to $-2.00 \mathrm{~V}$ versus $\mathrm{Fc}^{+} / \mathrm{Fc}$. On the basis of above analyses and literature precedents $[5,15,16,18,19]$, we also tried to propose the catalytic cycle depicted in Scheme 3 for the generation of $\mathrm{H}_{2}$ from acetic acid mediated by $\mathbf{1}$. One-electron reduction of $\left[(\mathrm{bpy})_{3} \mathrm{Ni}^{\mathrm{II}}\right]^{2+}$ provides a putative $\left[(\mathrm{bpy})_{2} \mathrm{Ni}^{\mathrm{I}}\right]^{+}$species by losing one bpy. Addition of hydrogen proton to $\left[(\text { bpy })_{2} \mathrm{Ni}^{\mathrm{I}}\right]^{+}$gives the $\mathrm{Ni}^{\mathrm{III}}-\mathrm{H}$ species. Then one-electron reduction of the $\mathrm{Ni}^{\mathrm{III}}-\mathrm{H}$ species affords $\mathrm{H}_{2}$, and further regenerates the starting complex 1. Although the relative contributions are indistinguishable in this analysis, we suspect that these processes are complementary $\mathrm{H}_{2}$ evolution pathways.

Fig. 3. CVs of a $0.48 \mathrm{mM}$ solution of complex 1, with varying concentration of acetic 
acid in $\mathrm{CH}_{3} \mathrm{CN}$. Conditions: $0.10 \mathrm{M}\left[\mathrm{n}-\mathrm{Bu}_{4} \mathrm{~N}\right] \mathrm{ClO}_{4}$ as supporting electrolyte, scan rate: $200 \mathrm{mV} / \mathrm{s}$, glassy carbon working electrode (1 mm diameter), Pt counter electrode, $\mathrm{Ag} / \mathrm{AgNO}_{3}$ reference electrode, Fc internal standard (*).
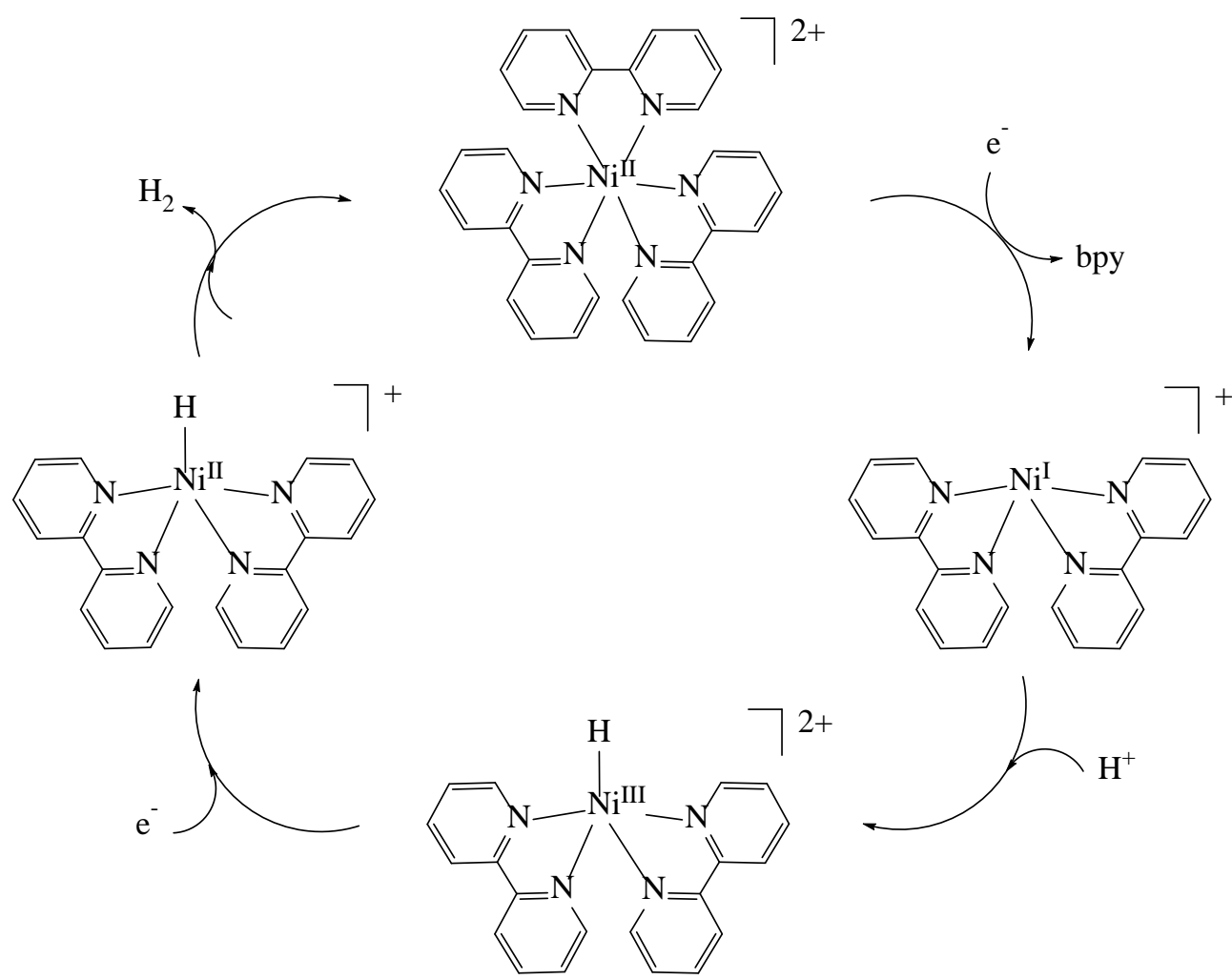

Scheme 3 The possible catalytic mechanism for proton reduction by complex 1

Several control experiments were carried out to verify that complex $\mathbf{1}$ is responsible for the catalysis. For example, acetic acid and $\mathrm{NiCl}_{2} \cdot 6 \mathrm{H}_{2} \mathrm{O}$ were each measured under identical conditions. As can be seen in Figs. S8-S9, the catalytic competency achieved with $\mathbf{1}$ is not matched by either acetic acid or $\mathrm{NiCl}_{2} \cdot 6 \mathrm{H}_{2} \mathrm{O}$ alone. Thus, a combination of the nickel center and bpy is essential for catalytic activity.

To further testify the catalytic activities of this complex, bulk electrolysis was conducted in $\mathrm{CH}_{3} \mathrm{CN}$ with acetic acid at variable applied potential. Fig. 4a showed the 
total charges of bulk electrolysis from complex $\mathbf{1}$ in the presence of acetic acid, and the charge significantly increased when the applied potential was set to more negative. When an applied potential was $-1.45 \mathrm{~V}$ versus $\mathrm{Ag} / \mathrm{AgNO}_{3}$, the maximum charge reached $123 \mathrm{mC}$ used 2 min, with accompanying evolution of a gas, which was confirmed as $\mathrm{H}_{2}$ by gas chromatography. According to Fig. S10, 0.05 mL of $\mathrm{H}_{2}$ was produced over an electrolysis period of $2 \mathrm{~h}$ under $-1.45 \mathrm{~V}$ versus $\mathrm{Ag} / \mathrm{AgNO}_{3}$. And a controlled-potential electrolysis (CPE) experiment under the same potential without 1 gave a charge of only $5 \mathrm{mC}$ (Fig. 4b), indicating that this coordinatively saturated complex does indeed serve as effective hydrogen producer under such conditions. From Equations (1) [20] and (2) [21], the TOF was estimated to be 152.88 moles of hydrogen per mole of catalyst per hour at an overpotential of $941.6 \mathrm{mV}$ (Eq. S1 and Fig. S11), which is higher than a coordinatively unsaturated nickel complex supported by 2,3-bis(2-hydroxybenzylideneimino)-2,3-butenedinitrile ligand that shows a TOF of 126 moles of $\mathrm{H}_{2}$ per mole of catalyst per hour at an overpotential of $941.6 \mathrm{mV}$ [16]. $\mathrm{TOF}=\Delta C /\left(\mathrm{F}^{*} n_{1} * n_{2} * t\right)$

Overpotential $=$ Applied potential $-\mathrm{E}^{\odot} \mathrm{HA}$

$$
\text { = Applied potential }-\left(\mathrm{E}^{\odot}{ }_{\mathrm{H}}^{+}-(2.303 R T / F) \mathrm{p} K_{a \mathrm{HA}}\right)
$$

Where, $\Delta C$ is the charge from the catalyst solution during CPE minus the charge from solution without catalyst during CPE; F is Faraday's constant, $n_{1}$ is the number of moles of electrons required to generate one mole of $\mathrm{H}_{2}, n_{2}$ is the number of moles of catalyst in solution, and $\mathrm{t}$ is the duration of electrolysis.

Fig. 4. (a) Charge buildup versus time from electrolysis of a $2.9 \mu \mathrm{M}$ complex 1 in 
$\mathrm{CH}_{3} \mathrm{CN}\left(0.10 \mathrm{M}\left[\mathrm{n}-\mathrm{Bu}_{4} \mathrm{~N}\right] \mathrm{ClO}_{4}\right)$ under various applied potentials. All data have been deducted blank. (b) Charge buildup versus time from electrolysis of a $0.10 \mathrm{M}$ $\left[\mathrm{n}-\mathrm{Bu}_{4} \mathrm{~N}\right] \mathrm{ClO}_{4}$ solution in $\mathrm{CH}_{3} \mathrm{CN}$ under $-1.45 \mathrm{~V}$ versus $\mathrm{Ag} / \mathrm{AgNO}_{3}$.

We then explored the electrocatalytic behavior in aqueous media. As shown in Fig. S12, in the presence of complex 1, an irreversible wave was observed at $-1.93 \mathrm{~V}$ versus $\mathrm{Ag} / \mathrm{AgCl}$ and the current strength increased with increasing concentrations of complex 1 from 0.00 to $6.0 \mu \mathrm{M}$. To further probe the nature of this reduction process, we investigated the $\mathrm{pH}$ dependence of the cathodic peak potential. From Fig. S13, the current strength increased significantly under lower $\mathrm{pH}$ values, which is consist with a catalytic process [22], indicating 1 also can catalyze water reduction to $\mathrm{H}_{2}$.

To further get the evidence for the activity in aqueous media, the bulk electrolysis of a $2.9 \mu \mathrm{M}$ complex $\mathbf{1}$ was conducted in a natural buffer under variable applied potentials. When an applied potential was $-1.45 \mathrm{~V}$ versus $\mathrm{Ag} / \mathrm{AgCl}$, the maximum charge was only $38 \mathrm{mC}$ during $2 \mathrm{~min}$ of electrolysis without complex $\mathbf{1}$ (Fig. 5a). Under the same conditions, the charge reached $1179 \mathrm{mC}$ with addition of complex 1 (Fig. 5b), accompanied by the appearance of gas bubbles which was confirmed to be $\mathrm{H}_{2}$ by GC analysis. From Fig. S14, 18.4 mL of $\mathrm{H}_{2}$ was obtained over an electrolysis period of $1 \mathrm{~h}$. According to Equations (1) and (3) [23], we also calculated the TOF for the catalyst as reaching a maximum of 1464 moles of hydrogen per mole of catalyst per hour at an OP of $837.6 \mathrm{mV}$ (Eq. S2).

Overpotential $=$ Applied potential- $\mathrm{E}(\mathrm{pH})=$ Applied potential- $(-0.059 \mathrm{pH})$ 
Fig. 5. (a) Charge buildup versus time from electrolysis of a $0.25 \mathrm{M}$ buffer (pH 7.0) under -1.45 V versus Ag/AgCl. (b) Charge buildup versus time from electrolysis of a $2.9 \mu \mathrm{M}$ complex 1 in a $0.25 \mathrm{M}$ buffer ( $\mathrm{pH}$ 7.0). All data have been deducted blank.

This electrocatalytic activity is higher than some other reported molecular nickel catalysts for $\mathrm{H}_{2}$ production from neutral water, including a dinickel complex supported by macrocyclic ligand that exhibits a TOF of 160 moles of $\mathrm{H}_{2}$ per mole of catalyst per hour at an OP of $820 \mathrm{mV}$ [24], and a coordinatively unsaturated nickel complex with 2,3-bis(2-hydroxybenzylideneimino)-2,3-butenedinitrile ion that achieves a TOF of 436 moles of $\mathrm{H}_{2}$ per mole of catalyst per hour at an OP of 837.6 $\mathrm{mV}[16]$.

In order to determine whether $\mathbf{1}$ retains activity over longer time periods, a $72 \mathrm{~h}$ $\mathrm{CPE}$ at $-1.45 \mathrm{~V}$ versus $\mathrm{Ag} / \mathrm{AgCl}$ was conducted in a neutral buffer with $2.9 \mu \mathrm{M}$ complex 1. As shown in Fig. S15, this nickel complex affords a charge build-up over time. After a $60 \mathrm{~h}$ electrolysis period, a total of $760 \mathrm{C}$ was passed and the $\mathrm{pH}$ had increased by 3.2 units (from 7.0 to 10.2), consistent with accumulation of $\mathrm{OH}^{-}$by water reduction, $2 \mathrm{H}_{2} \mathrm{O}+2 \mathrm{e} \rightarrow \mathrm{H}_{2}+2 \mathrm{OH}^{-}$. As shown in Fig. S16, the intensities of the absorption bands at 241 and $295 \mathrm{~nm}$ increase during $60 \mathrm{~h}$ of electrochemical reduction of complex 1 under $-1.45 \mathrm{~V}$ versus $\mathrm{Ag} / \mathrm{AgCl}$, but the peak position does not change, indicating the catalyst is stable under these conditions. This result is in agreement with results from the repeated CPE, the original catalytic function was recovered and could be repeated several times when the solution $\mathrm{pH}$ was adjusted back to the original 7.0. 
We have successfully prepared a new kind of electro-catalyst by employing a coordinately saturated nickel(II) complex with a unknown redox-active mechanism. Interestingly, this coordinatively saturated complex can electrocatalyze $\mathrm{H}_{2}$ production both from acetic acid and aqueous buffer. Note, during the synthesis of the nickel complex, TCNE indeed exhibits its versatile reactivity in different direction and provides a pentacyanopropenide species. Ongoing efforts are focused on the study of the catalytic mechanism for proton or water reduction by coordinately saturated complex.

\section{Acknowledgements}

This work was supported by the National Science Foundation of China (No. 20971045 and 21271073).

\section{References}

[1] W. Kaim, M. Moscherosch, Coord. Chem. Rev. 129 (1994) 157-193.

[2] J. S. Miller, Angew. Chem. Int. Ed. 45 (2006) 2508-2525.

[3] J. D. Bagnato, W. W. Shum, M. Strohmeier, D. M. Grant, A. M. Arif, J. S. Miller, 
Angew. Chem. Int. Ed. 45 (2006) 5322-5326.

[4] L. Z. Tang, C. N. Lin, S. Z. Zhan, X. H. Xie, Inorg. Chem. Commun. 69 (2016) $16-19$.

[5] C. N. Lin, S. T. Ren, L. P. Ye, C. H. Chen, S. Z. Zhan, Inorg. Chem. Commun. 69 (2016) 24-27.

[5] G. Wang, H. Zhu, J. Fan, C. Slebodnick, G. T. Yee, Inorg. Chem. 45 (2006) 1406-1408.

[6] J. S. Miller, A. J. Epstein, Angew. Chem. Int. Ed. Engl. 33 (1994) 385-415.

[7] J. M. Manriquez, G. T. Yee, R. S. McLean, A. J. Epstein, J. S. Miller, Science 252 (1991) 1415-1417.

[8] G. T. Yee, J. M. Manriquez, D. A. Dixon, R. S. McLean, D. M. Groski, R. B. Flippen, K. S. Narayan, A. J. Epstein, J. S. Miller, Adv. Mater. 3 (1991) 309-311.

[9] J.-H. Her, P. W. Stephens, K. I. Pokhdnya, M. Bonner, J. S. Miller, Angew. Chem. Int. Ed. 46 (2007) 1521-1524.

[10] Synthesis of complex 1: To a stirred solution of 2,2-bipyridine (0.350 g, 2 mmol) and $\mathrm{NiCl}_{2} \cdot 6 \mathrm{H}_{2} \mathrm{O}(0.238 \mathrm{~g}, 1 \mathrm{mmol})$ in $20 \mathrm{ml}$ methanol, TCNE $(0.204 \mathrm{~g}, 2 \mathrm{mmol})$ in methanol $(10 \mathrm{ml})$ was added and the mixture was further stirred for $2 \mathrm{~h}$. Green crystals were obtained from the filtrate which was allowed to stand at room temperature for several days, collected by filtration, and dried in vacuo (0.59 g). Calcd for $\mathrm{C}_{46} \mathrm{H}_{24} \mathrm{~N}_{16} \mathrm{Ni}$ : C, 64.28; H, 2.81; N, 26.07; Found: C, 64.85; H, 2.80; N, 26.33.

[11] C. Kremer, C. Melián, J. Torres, M. P. Juanico, C. Lamas, H. Pezaroglo, E. 
Manta, H. Schumann, J. Pickardt, F. Girgsdies, O. N. Ventura, F. Lloret, Inorg. Chim. Acta 314 (2001) 83-90.

[12] F. Conan, B. L. Gall, J.-M. Kerbaol, S. L. Stang, J. Sala-Pala, Y. L. Mest, J. Bacsa, X. Ouyang, K. R. Dunbar, C. F. Campana, Inorg. Chem. 43 (2004) 3673-3681.

[13] A. J. Fatiadi, Synthesis (1986) 249-284.

[14] W. M. Singh, T. Baine, S. Kudo, S. Tian, X. A. N. Ma, H. Zhou, N. J. DeYonker, T. C. Pham, J. C. Bollinger, G. L. Baker, B. Yan, C. E. Webster, X. Zhao, Angew. Chem. Int. Ed. 51 (2012) 5941-5944.

[15] M. L. Helm, M. P. Stewart, R. M. Bullock, M. R. DuBois, D. L. DuBois, Science 333 (2011) 863-866.

[16]. J. P. Cao, T. Fang, L. Z. Fu, L. L. Zhou, S. Z. Zhan, Int. J. Hydrogen Energy 39 (2014) 10980-10986.

[17] H. I. Karunadasa, C. J. Chang, J. R. Long, Nature 464 (2010) 1329-1333.

[18] D. Xue, Q. Y. Lv, C. N. Lin, S. Z. Zhan, Polyhedron 117 (2016) 300-308.

[19] Y. X. Zhang, L. Z. Tang, Y. F. Deng, S. Z. Zhan, Inorg. Chem. Commun. 72 (2016) 100-104.

[20] L. Tong, R. Zong, R. P. Thummel, J. Am. Chem. Soc. 136 (2014) 4881-4884.

[21] G. A. N. Felton, R. S. Glass, D. L. Lichtenberger, D. H. Evans, Inorg. Chem. 45 (2006) 9181 -9184.

[22] R. S. Nichloson, I. Shain, Anal. Chem. 36 (1964) 706-723.

[23] Y. Sun, J. P. Bigi, N. A. Piro, M. L. Tang, J. R. Long, C. J. Chang, J. Am. Chem. 
Soc. 133 (2011) 9212-9215.

[24] J. P. Collin, A. Jouaiti, J. P. Sauvage, Inorg. Chem 27 (1988) 1986-1990. 

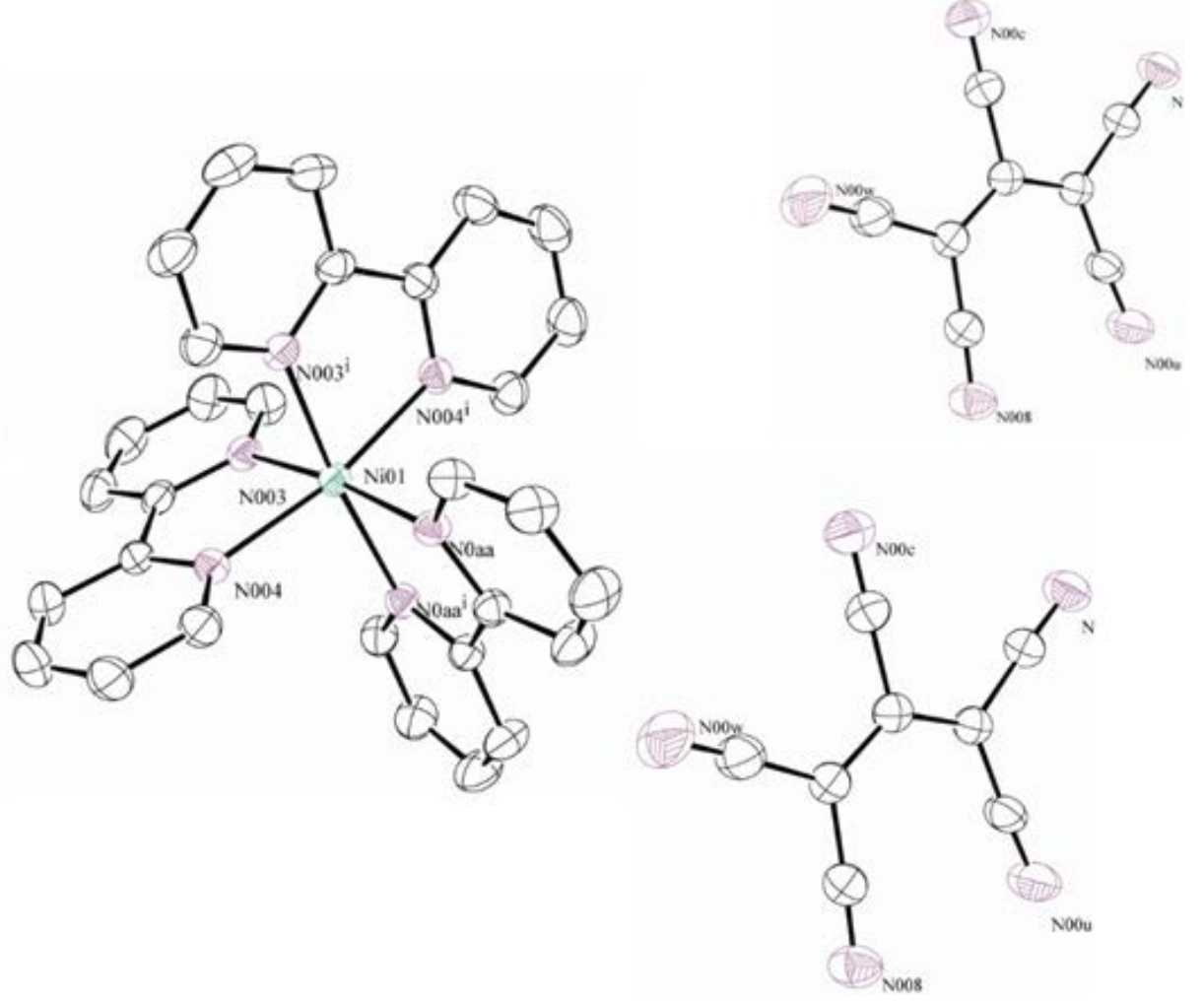

Fig. 1. ORTEP drawing of complex 1 with thermal ellipsoids on the 50\% probability level (hydrogen atoms are not shown). 


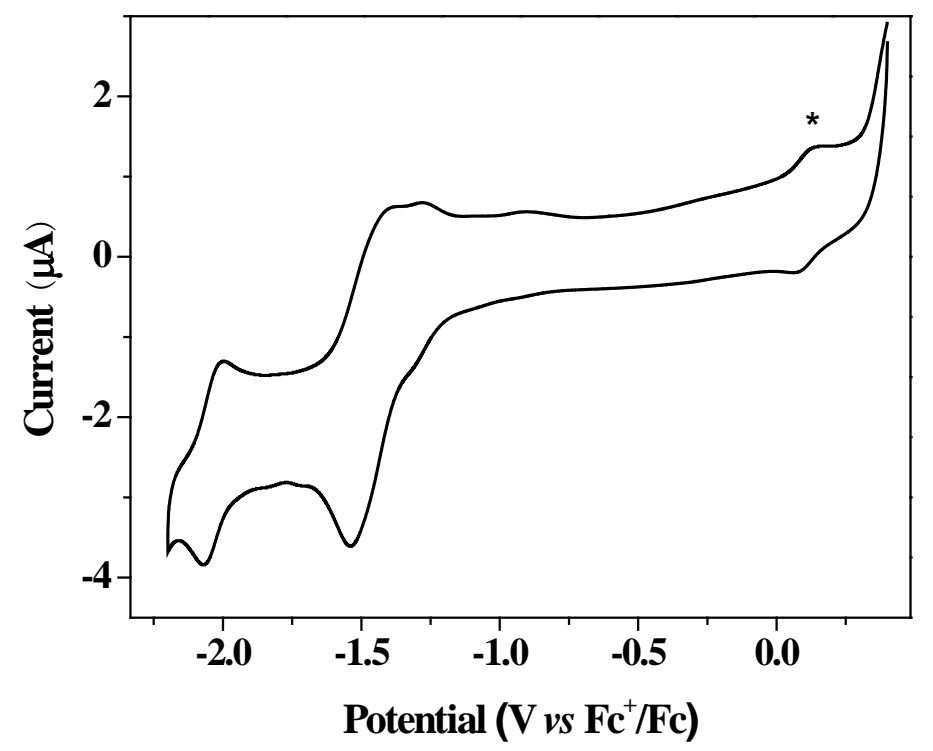

Fig. 2. Cyclic voltammogram (CV) of $0.48 \mathrm{mM}$ complex 1 in $\mathrm{CH}_{3} \mathrm{CN}$. Conditions: room temperature, $0.10 \mathrm{M}\left[\mathrm{n}-\mathrm{Bu}_{4} \mathrm{~N}\right] \mathrm{ClO}_{4}$ as supporting electrolyte, scan rate: 100 $\mathrm{mV} / \mathrm{s}$, glassy carbon working electrode (1 mm diameter), Pt counter electrode, $\mathrm{Ag} / \mathrm{AgNO}_{3}$ reference electrode. Ferrocene internal standard (*). 


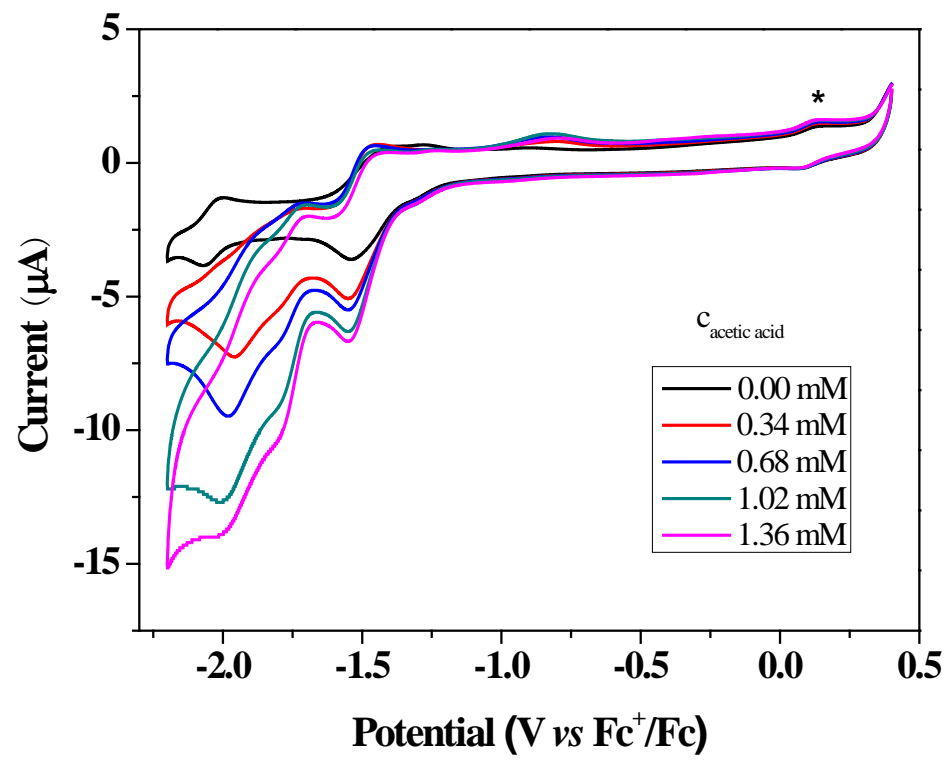

Fig. 3. CVs of a $0.48 \mathrm{mM}$ solution of complex 1, with varying concentration of acetic acid in $\mathrm{CH}_{3} \mathrm{CN}$. Conditions: $0.10 \mathrm{M}\left[\mathrm{n}-\mathrm{Bu}_{4} \mathrm{~N}\right] \mathrm{ClO}_{4}$ as supporting electrolyte, scan rate: $200 \mathrm{mV} / \mathrm{s}$, glassy carbon working electrode (1 mm diameter), Pt counter electrode, $\mathrm{Ag} / \mathrm{AgNO}_{3}$ reference electrode, Fc internal standard (*). 

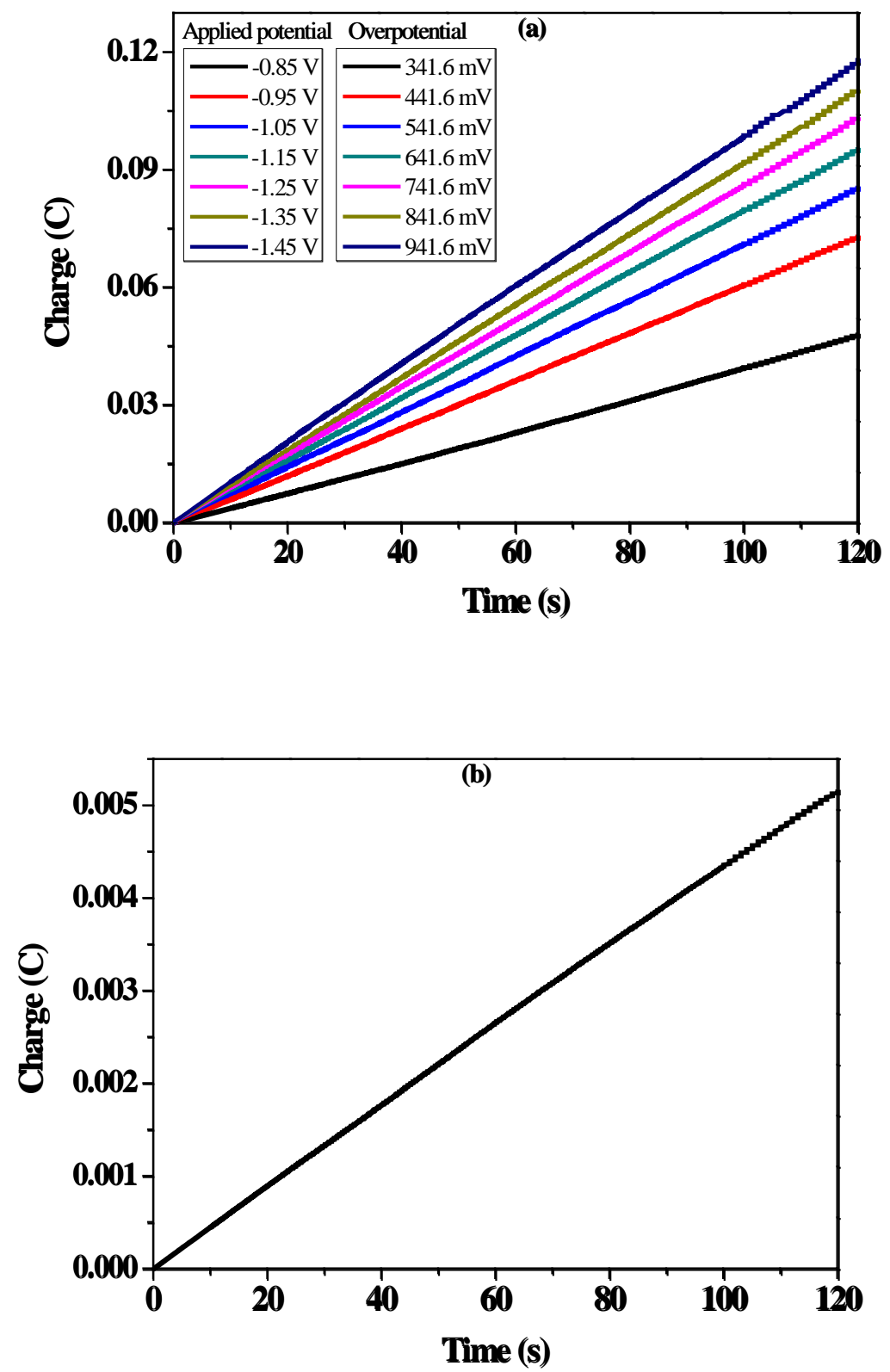

Fig. 4. (a) Charge buildup versus time from electrolysis of a $2.9 \mu \mathrm{M}$ complex 1 in $\mathrm{CH}_{3} \mathrm{CN}\left(0.10 \mathrm{M}\left[\mathrm{n}-\mathrm{Bu}_{4} \mathrm{~N}\right] \mathrm{ClO}_{4}\right)$ under various applied potentials. All data have been deducted blank. (b) Charge buildup versus time from electrolysis of a $0.10 \mathrm{M}$ $\left[\mathrm{n}-\mathrm{Bu}_{4} \mathrm{~N}\right] \mathrm{ClO}_{4}$ solution in $\mathrm{CH}_{3} \mathrm{CN}$ under $-1.45 \mathrm{~V}$ versus $\mathrm{Ag} / \mathrm{AgNO}_{3}$. 

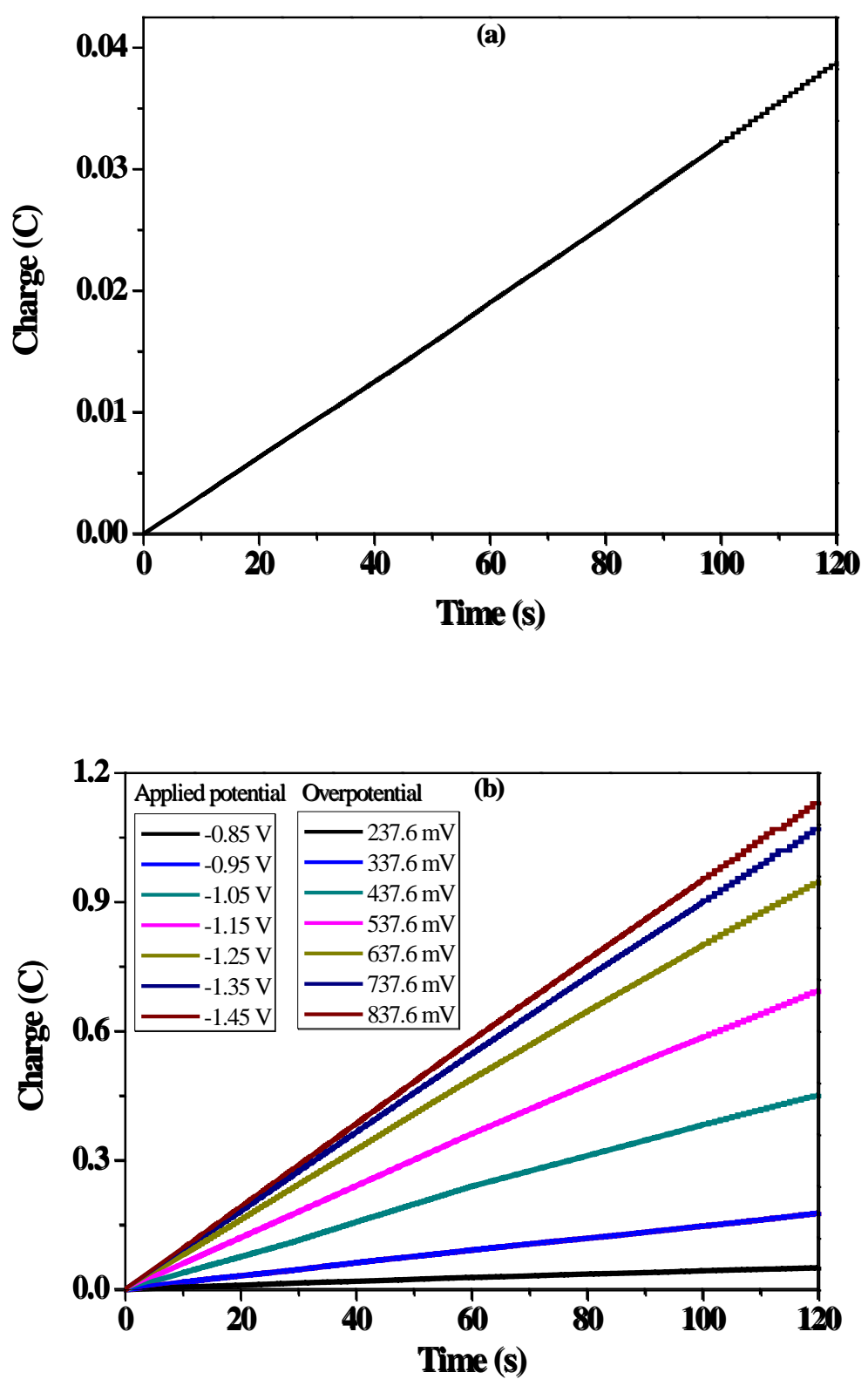

Fig. 5. (a) Charge buildup versus time from electrolysis of a $0.25 \mathrm{M}$ buffer ( $\mathrm{pH} 7.0$ ) under $-1.45 \mathrm{~V}$ versus $\mathrm{Ag} / \mathrm{AgCl}$. (b) Charge buildup versus time from electrolysis of a $2.9 \mu \mathrm{M}$ complex 1 in a $0.25 \mathrm{M}$ buffer ( $\mathrm{pH}$ 7.0). All data have been deducted blank. 


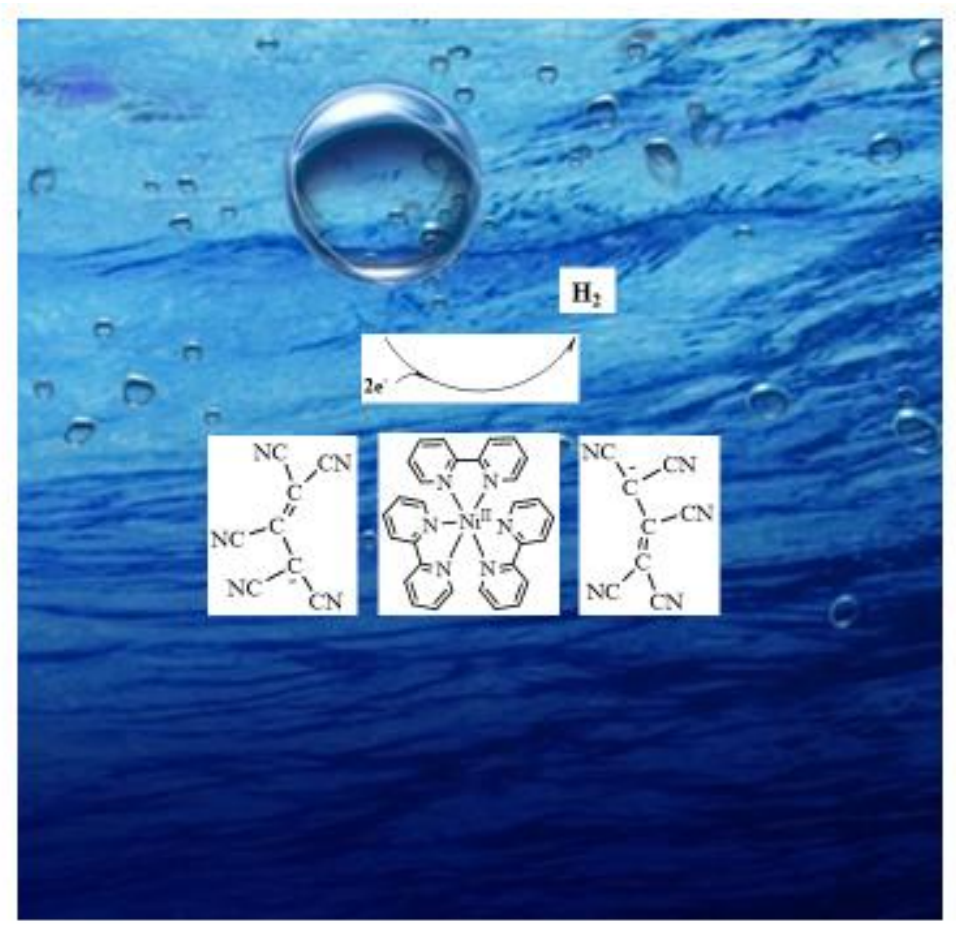

